\title{
(RE)CONSIDERING POSTGRADUATE EDUCATION AND SUPERVISION IN THE KNOWLEDGE SOCIETY
}

\section{Magda Fourie-Malherbe, Claire Aitchison, Eli Bitzer \& Ruth Albertyn}

The title of this publication, Postgraduate supervision: Future foci for the knowledge society, locates higher education - and more specifically, postgraduate education and supervision - explicitly within discourses on the knowledge society. The aim of this volume is to employ this concept of the knowledge society and its corollary, the knowledge economy, as a heuristic for (re)considering the forms and purposes of postgraduate education and supervision in relation to contemporary realities and future possibilities. Thus the edition will be of interest to a wide range of postgraduate education stakeholders: national and institutional policy makers will value the broad range of up-to-date comparative case studies, while those at the coal-face - supervisors, support staff and students - will appreciate the many and varied renditions of postgraduate experiences at various 'local' sites. Key international and local authors combine in this edition to create a unique mix of global and local voices - some already well known, plus newer commentators. The chapters have been selected to provide a rich and nuanced balance of country and personal perspectives and experiences that explore and theorise contemporary concerns within the sector.

The creation, exchange and use of knowledge define contemporary societies. Policy and social discourses have, for some time, promoted the concept of a knowledge society as the driver for change and for globalisation. From a neo-liberal perspective this conception sees knowledge as a commodity with powerful economic implications for competing nations seeking economic advantage. Education is central to the knowledge economy for producing knowledge workers to "develop human capital in knowledge industries" (Danby \& Lee 2012:4). In doctoral education, the literature routinely refers to the imperatives of the global 'knowledge economy' as the key 


\section{POSTGRADUATE SUPERVISION • FUTURE FOCI FOR THE KNOWLEDGE SOCIETY}

rationale for change and expansion of doctoral programmes worldwide (Golde \& Walker 2006; Boud \& Lee 2009; Taylor 2012; Nerad \& Evans 2014). What is clear from these discussions about the role of knowledge creation and dissemination is that the contributions of doctoral education are increasingly seen as inextricably tied to the perceived fortunes and futures of nations (Croussard 2013).

Whereas Scott (2015) establishes a close link between higher education and the knowledge society by referring to knowledge societies as 'graduate societies', Välimaa and Hoffman (2008:269) emphasise a broader interpretation by saying that "the knowledge society aims to describe a new situation in which knowledge, information and knowledge production are defining features of relationships within and among societies, organisations, industrial production and human lives". By framing the knowledge society in the context of associations and interactions at various levels, the authors draw attention to both global and local dimensions of the phenomenon. Since this book brings together postgraduate education perspectives and practices from different parts of the world, contributing authors from international and national (South African) backgrounds were invited to submit chapters on the basis of their scholarly work in the field. Also, no particular country or region was prioritised.

The volume is divided into six parts on the basis of addressing different questions or issues that find coherence in the arguments about the purposes and practices of postgraduate education. Part 1 'From the global to the local' is concerned with how global contexts link with local contexts while Part 2 'How postgraduate students are supported towards success' deals with policy, practice and structures for postgraduate success. In Part 3 'What both supervisors and postgraduate students expect from the doctoral experience' the focus is on research education experiences. Both Part 4 'Innovations in postgraduate supervision' and Part 5 'New forms of doctoral education' grapple with doctoral education processes and their implications for the knowledge economy. To conclude the book, Part 6 'Supervisor experiences and identities' addresses issues particularly related to the being and becoming of postgraduate supervisors.

In Part 1, Pam Denicolo (Chapter 2) sets the international scene by referring to global developments in doctoral education and noting the implications for communities of practice involved in this qualification. She highlights the consistency of concerns despite diversity between contexts and structures. These concerns relate to the changing higher education context and the focus on quality assurance, both of which hold implications for researcher development, relevant support and appropriate training. The dilemmas and contradictions raised by Denicolo challenge role-players 
to reflect on experiences of researchers, the role of managers of institutions, leaders of schools, centres and partnerships, as well as supervisors and examiners. Denicolo challenges readers to balance tensions and retain focus on the purpose of doctoral education in the current global context.

On the same plane, Claire Aitchison (Chapter 3) uses a neo-liberal framing to explore how technological and global changes in doctoral education have an impact on doctoral writing. By examining the interests of diverse stakeholders, Aitchison's account of higher education research identifies the interplay of both homogenising and differentiating trends at the global and local level. She considers what doctoral writing is, and can be, in the new context of digitised knowledge creation, consumption and dissemination - and the implications for institutions, supervision and doctoral scholars.

At the local level, Johann Mouton (Chapter 4) demonstrates how a country such as South Africa is addressing the global imperatives of the knowledge economy. He presents a detailed account of the trends, challenges and constraints on doctoral education as South African institutions (and supervisors and students) respond to four, often competing, discourses or 'imperatives' for change: growth, transformation, quality and efficiency. Mouton's research shows that although doctoral education in South Africa has achieved impressive growth and transformation over the last decade, inequalities and conflicting impacts on quality and efficiency remain.

Whereas the discussion in Part 1 seems to underscore a 'neo-liberal paradigm' of higher education, in other words, "the idea of higher education as an essential part of the 'knowledge economy', a producer of knowledge and skills for economic competitiveness and a facilitator of private interests" (Singh 2015:60), Scott (2015:55) makes the point that students' participation in higher education is also "highly desirable in terms of the ability to fully function as a social and civic actor". This brings us to the second discourse highlighted by Singh (2015:60): that higher education is a public good, "a contributor to achieving broader public purposes which encompass but are not reducible to narrowly framed economic goals and private interests". Croussard (2013) also refers to the social aspects of research which go beyond individual skill acquisition. A number of scholars advocate these broader perspectives: Biesta (2007:467, cited in Singh 2015:60) coined the term 'knowledge democracy' to characterise this role of higher education, and Brew (2015) highlights the 'New Growth view' of higher education. This perspective "regards the public good in terms of the contribution of higher education to the growth of knowledge both of the individual and of the society as a whole... Such a 


\section{POSTGRADUATE SUPERVISION • FUTURE FOCI FOR THE KNOWLEDGE SOCIETY}

view places more emphasis on what the student knows and can do as a consequence of his or her university experience" (Brew 2015:101).

Turning our attention now to what postgraduate students 'know' and 'can do' as a result of a postgraduate experience, we need to acknowledge some major shifts. In the past, the doctorate, and to a lesser extent the master's degree, were primarily seen as qualifications preparing people for academic careers. Now, in knowledge societies, the doctorate is increasingly seen as a high-level qualification that trains people for a much wider variety of positions including those beyond the university (McAlpine, Amundsen \& Turner 2013; Boud, Brew, Dowling, Kiley, McKenzie, Malfroy, Ryland \& Solomon 2014). The intellectual, academic, technical and personal and professional management skills typically developed and inculcated through postgraduate studies enable doctoral candidates to become creative, critical and autonomous intellectual risk-takers (LERU 2010). Such flexibility, skills and attributes are increasingly important in contemporary workplaces as is the need for rigorous, well-informed and effectively executed research in organisations across the public, private and non-profit sectors. Furthermore, increasingly informationdense societies benefit from members who can assemble, interpret and manage large amounts of evidence for complex decision making (Croussard 2013).

These changing conditions and needs of both the knowledge economy and the knowledge democracy require postgraduate supervisors to think creatively about their programmes and practices while postgraduate students need to reconsider their motivations and the possible outcomes from their postgraduate experiences. How could the postgraduate experience and postgraduate supervision be shaped to deliver a renewal of the academic profession, and also build the highly skilled workforce and creative, critical citizenship required in knowledge societies? What are the implications for our points of departure and practices? How will this affect our identities?

In Part 2, Paul Prinsloo (Chapter 5) proposes a socio-critical model which maps and explores the intersecting interactions at different phases in the doctoral journey. He conceptualises the factors that have an impact on success as a result of mostly non-linear, multidimensional, interdependent interactions between various roleplayers and contexts. The socio-critical model for understanding student success and retention was developed from six identified constructs flowing from the work of Bourdieu (1987). Viewing success and retention through a socio-critical lens provides a more holistic, multi-dimensional perspective of postgraduate education.

At the level of practice, Johann Groenewald and Cindy Steenekamp (Chapter 6) document one example of an institutional initiative to establish a doctoral graduate 
school programme in South Africa. Relevant well beyond the borders of South Africa, they provide a history and rationale for their approach with evidence of its successes and shortcomings over time. Along with author reflections, this account provides sufficient details on the structure and functions of the Graduate School model so that others could emulate and improve on these experiences.

Another practical issue under scrutiny in Part 2 is the issue of plagiarism and research integrity in postgraduate studies. Nonnie Botha (Chapter 7) highlights this knowledge gap by reporting on a small South African research project that combined literature, institutional policies and workshop data to produce a set of approaches for responding to plagiarism in postgraduate research studies. The resultant framework offers a valuable approach to those seeking to embed integrity into research training.

The contributions in Part 3 of the book highlight how expectations of postgraduate students and supervisors are changing. Lorna Moxham and her co-authors (Chapter 8) relate the expectations for timely completion to compliance and funding imperatives. They posit that articulating clear expectations about supervision from the beginning of the research journey could contribute to timely completion. Their chapter reports on a multi-country study done by means of a survey of both supervisors and postgraduate students to examine their expectations with regard to research on higher degree studies. They found that many expectations differ significantly between supervisors and students, underscoring the importance of articulating expectations from the beginning.

A similar theme is explored in Chapter 9 ('Mutual expectations in the postgraduate doctoral supervisory relationship') by Hesta Friedrich-Nel and Joyce MacKinnon. In their chapter they suggest strategies to mitigate the mismatch in doctoral supervisorstudent expectations with regard to the supervisory relationship. Their case study demonstrates that supervisors and students need to clarify and discuss their expectations initially and on an ongoing and regular basis, in order to create an environment where students can grow and develop as confident professionals able to challenge their supervisors.

The increasing numbers of mature students enrolling for advanced qualifications in business schools provide an example of industry's appetite for postgraduate qualifications. These students often experience challenges with research due to their primary outcome focus on knowledge gain for efficiency in their work. External practitioners are increasingly contracted for postgraduate supervision with implications for research quality and support. In Chapter 10, Ruth Albertyn, Salome van CollerPeter and John Morrison discuss how they applied an interactive qualitative analysis 


\section{POSTGRADUATE SUPERVISION • FUTURE FOCI FOR THE KNOWLEDGE SOCIETY}

research design to identify both student and supervisor perspectives of research challenges. The study concluded that appropriate and effective responses to these challenges could contribute not only to improving throughput of postgraduate students but also to enhancing transferable skills which could influence evidencebased practice and quality of graduates in the workplace.

The above-mentioned dual democratic and economic discourse (Singh 2015) has contributed to increasing numbers of mid-career professionals in academe undertaking postgraduate studies. The pressures associated with this additional burden served as motivation for the comparative study of academics in the United Kingdom and South Africa by Brenda Leibowitz, Gina Wisker and Pia Lamberti (Chapter 11). Participants were mainly professional or vocational rather than traditionally academic and they reported similar challenges in both professional and academic contexts. These authors point to the importance of valuing and balancing academic and application knowledge practices and providing appropriate institutional support when mid-career academics embark on postgraduate studies.

Another comparative study, conducted at four research-intensive Swedish and South African universities, is reported on in Chapter 12 by Liezel Frick, Ruth Albertyn, Eva Brodin, Silwa Claesson and Sioux McKenna. This study explored how doctoral students make the transition into scholarly practice as early career academics, and more particularly how doctoral education prepares doctoral candidates for an academic career. Despite distinct contextual institutional and national differences, the similarities in respondents' experiences proved to be significant. The study found that whereas doctoral candidates appreciated the freedom to develop their own knowledge projects during the doctoral research process, once they entered the highly complex and demanding higher education environment as academics, their sense of freedom and independence diminished. The authors come to the conclusion that the doctorate by itself does not sufficiently prepare early career academics for an academic career, but that multiple support structures including supervisors, external mentors and carefully designed induction programmes are required.

Contributions in both Part 4 ('Innovations in postgraduate supervision') and Part 5 ('New forms of doctoral education') grapple with the implications of the knowledge economy and the 'boundarylessness' of the knowledge society for postgraduate education and supervision. Välimaa and Hoffman (2008) suggest that in knowledge societies, universities, traditionally the primary producers and conveyors of knowledge, have become only one player in a network of bodies that generate, apply and disperse knowledge. The 'boundarylessness' of the knowledge economy 
is explicated as follows by the League of European Research Universities (LERU 2010:4):

The big intellectual challenges which confront the world do not recognise boundaries. Knowledge is developed, marshalled, and disseminated in international fora and congresses. Cross-fertilisation between disciplines breeds much of the new thinking in the modern world. Major challenges for society feed research in our universities, and findings of university research are tailored and exploited in society. The business of research and innovation in the knowledge economy is therefore international, interdisciplinary and increasingly intersectoral ...

Nevertheless, UNESCO (2005:87) argues that higher education institutions are still "destined to play a fundamental role in knowledge societies, based on radical changes in the traditional patterns of knowledge production, diffusion and application". Parts 4 and 5 explore what this 'fundamental role' is, and the implications for postgraduate education and supervision.

The tension between the traditional purposes of the $\mathrm{PhD}$ and the pressures of the knowledge economy for particular kinds of output can be seen at the core of what a doctorate is - and how we assess 'doctorateness'. In Chapter 13, Eli Bitzer, Shosh Leshem and Vernon Trafford address these tensions. Building on earlier work, this project sought to identify the learning resulting from three phases of 'doctorateness interventions' for doctoral students and supervisors from 15 South African universities. Participants experienced positive long-term transformative learning, reporting on changed approaches and behaviours including emphasising the endpoint of doctorateness, while valuing doctorateness as a concept and a process. The study highlighted the importance of incorporating principles of adult transformative learning into such interventions and across the whole of candidature.

The key role of innovation in the knowledge society has spawned the need for innovative thinking around research. David Plowright's chapter (Chapter 14) describes a novel way of approaching research methodology. He asserts that in the knowledge society, the emphasis of research has changed from disciplinary-focused scholarship to instrumental knowledge useful for solving real world problems. This shift in focus calls for a reconceptualisation of research to respond to this changing emphasis. In his chapter, Plowright thus proposes a practically and conceptually manageable integrated framework (FraIM) to meet the needs of rigour and usefulness in both academic and workplace research.

A further innovation related to research methodology is reported by Martie Mearns and Riaan Loots (Chapter 15). They propose a joint approach between pedagogy and technology and describe the design and development of an online collaborative 


\section{POSTGRADUATE SUPERVISION • FUTURE FOCI FOR THE KNOWLEDGE SOCIETY}

platform for teaching and learning research methodology at a postgraduate level. The authors propose that collaborative platforms and subsequent development of knowledge repositories could relieve the strain on institutional resources by creating a collective collaborated peer- and expert-reviewed knowledge source.

Another example of using online spaces in postgraduate research education is found in the chapter by Cally Guerin, Claire Aitchison and Susan Carter (Chapter 16). Here they focus on harnessing social media and the novelty of blogging to support doctoral writing which extends beyond the supervision relationship. They explore participatory pedagogies in the process of co-creation of knowledge amongst this unique community who have an interest in doctoral education. The authors describe the DoctoralWriting SIG blog and reflect on the outcomes of this innovation which they state opens a positive space and widens doctoral support as various role-players actively join the digital discussion.

To emphasise the importance of writing in research further, Lucia Thesen takes a novel approach to postgraduate writing in Chapter 17 entitled 'Laughter, surface tension and learning from postgraduate writers' circles'. The chapter explains how a postgraduate writing circle emerged and what took place within it. The complexity and delicacy of such writers' circles is explored by looking at laughter and affect. Thesen sees these as embodied feeling, consequently deflating the traditional disembodied, cerebral image of the researcher and of theory itself. She then goes on to examine the writing circle through the metaphor of 'surface tension'. She uses this image to explain the life of the writing circle and also the core activity of the circle - writing - showing how surface tension expresses the affect around writing, as well as the ambiguity of forces that tug in different directions.

Part 5 introduces new forms of doctoral education responding to many of the issues highlighted above. Liezel Frick (Chapter 18) for instance, discusses the PhD by publication, a relatively recent phenomenon, particularly in the humanities and social sciences. Using a dataset of 1129 doctoral theses covering a seven-year period at one South African research-intensive university, the author found much diversity in formats across faculties and even within faculties. Frick shows that there was no strict adherence to institutional guidelines governing the PhD by publication at the chosen university. As an initial analysis, the study opens opportunities for further research and finer grained analyses in the $\mathrm{PhD}$ by publication. The chapter also indicates that diversity in $\mathrm{PhD}$ formats has implications for doctoral pedagogy, supervisory capacity, institutional policy and institutional funding, and suggests that debates on the PhD by publication have not yet addressed the issue of whose interests 
are primarily served by publishing during the PhD - institutional stature and ranking, supervisors' academic standing, or the scholarly development of the student?

The matter of joint degrees as another new form of doctoral education is interrogated by Magda Fourie-Malherbe, Jan Botha and Dorothy Stevens (Chapter 19). They report on an investigation into the rationale, challenges and benefits of joint degrees among supervisors and doctoral candidates at one South African university. Using a conceptual framework adapted from the work of McAlpine and Norton (2006), they found that benefits and challenges could be identified at four levels: the system, institution, department/discipline and individual. There was general agreement that the benefits for the national science system, the institutions, and more particularly the departments, supervisors and students involved, far outweighed the challenges some students faced. Benefits around employability, networking, international and inter-institutional collaboration and academic mobility were highlighted, strongly resonating with the expectations of the knowledge society.

In Chapter 20, 'The 'creative-minded supervisor': gatekeeping and boundarybreaking, supervising creative doctorates', Gina Wisker and Gillian Robinson explore the tension between the highly valued qualities of creativity and risk-taking, and the realities of nurturing these qualities within doctoral supervision. They draw on numerous examples of supervisor self-reports to provide a fascinating account of innovative practices that have been used to protect and nurture creative doctoral experiences in safe and supported environments.

A timely assessment of trends in South African postgraduate higher education research is presented in Chapter 21. Co-authors Annette Wilkinson, Deidre van Jaarsveldt, Elrita Grimsley and Limpho Seoka use expanded versions of Malcolm Tight's (2003) and Bitzer and Wilkinson's (2009) frameworks for studying higher education scholarship. They identified 11 themes for higher education research in South Africa showing various shifts and trends; most notably toward a greater interest in the student experience. In addition, they were able to illustrate the growing vibrancy and diversity of disciplinary interest in higher education research. On the other hand, however, unfortunately they note an alarming lack of interest in postgraduate supervision.

Part 6 focuses on supervisor experiences and identities. Anisa Vahed (Chapter 22) gives a narrative account of the supervisory relationship between herself as a doctoral candidate and her two supervisors. She describes the research difficulties that emerged during an interdisciplinary study journey, how these obstacles were negotiated and the success of the supervision combination. By using characters from video games as pedagogical tools the author analysed the supervision approaches 


\section{POSTGRADUATE SUPERVISION • FUTURE FOCI FOR THE KNOWLEDGE SOCIETY}

of her supervisors, which helped to deconstruct her thinking. She demonstrated how the contrasting skills of her supervisors facilitated her epistemological access into research and influenced her own personal development as a research student. Even though the chapter does not provide a generalised theoretical account of cosupervision, its reflective, auto-ethnographic narrative offers valuable insights into how different cognitive knowledge, languages and methodologies from different disciplinary traditions can be brought together in effective and useful co-supervision.

In response to the performativity and regulation of the neo-liberal higher education context, Jeanette Maritz and Paul Prinsloo (Chapter 23) examine how 'academic capitalism' has been shaping supervisory roles and undertakings by describing their own academic and supervisory journeys. They attempted to claim back their narratives and provide a counter-narrative, that of the supervisor entering from the margins underprepared for the various roles and responsibilities, or what they call the 'academic nomad'. They conclude that in the context of the 'academic revolution' characterised by 'academic capitalism' nomadic identities may well become the new normal in the future career trajectories of supervisors in doctoral education, and as such, may alter the rules of the game and challenge the current master codes.

In his concluding chapter on the future of doctoral education, Michael Samuel (Chapter 24) challenges higher education to think about the kind of support needed for current and future interconnected doctoral students who are part of rapidly changing knowledge expansion within a larger community of scholars. He argues that postgraduate studies in a knowledge society should centre on being responsive to the local and global context and employ innovative practices to address the expectations and experiences of multiple role-players, and, in so doing, extend knowledge production for the common good.

\section{CONCLUSION}

The 24 chapters in six related parts contained in this volume provide diverse but also congruent perspectives on future foci for research into postgraduate education and supervision in the knowledge society.

What seems clear overall is that greater diversity of purposes, forms and genres of postgraduate production will become the order of the day in vibrant and productive knowledge societies. Postgraduate success will be increasingly considered as nonlinear, multidimensional and interdependent, where the governance of postgraduate studies may take a variety of forms. There will be an increased range of expectations for postgraduate studies and for the doctorate in particular, where an array of relational issues, candidate support and transitions into early careers - both within 
and outside the academy - will prevail. Various methodological options will be required to better respond to complex local and global problems. A diversity of postgraduate degree programmes - including joint degrees - will thus refocus attention to effective and productive postgraduate pedagogies relevant to particular regional, national and institutional contexts.

From a more congruent perspective, future research into postgraduate education and supervision will be increasingly levelled at quality issues, questions of growth, the efficiency of postgraduate systems and, in many countries and institutions, will also include elements of equity, justice and affordability. Increasingly, common ground will be sought on what constitutes, for instance, a quality doctorate, while the benefits of the co-creation of knowledge, joint writing, technological innovation and support, and participatory pedagogies will be further explored. Knowledge economies will also, and increasingly, require creative and innovative postgraduate work; at the same time, notions of academic capitalism and academic nomads will become more commonplace as academic and university operations become increasingly expensive and financially unsustainable. This state of affairs will add to new interests in knowledge production that will challenge old ways of writing and disseminating research, and to new studies into how postgraduate research education may become more relevant and useful to economic and social development.

If one takes heed of the pointers highlighted by the different contributors to this volume, it may well provide for a rich source in identifying future research possibilities and agendas in gearing up postgraduate research education and supervision for the knowledge society which is upon us already.

\section{REFERENCES}

Bitzer E \& Wilkinson A. 2009. Higher education as a field of study and research. In: E Bitzer (ed). Higher education in South Africa: A scholarly look behind the scenes. Stellenbosch: SUN MeDIA. 369-408.

Boud D \& Lee A. 2009. Changing practices of doctoral education. Abingdon, Oxon: Routledge.

Boud D, Brew A, Dowling R, Kiley M, McKenzie J, Malfroy J, Ryland K \& Solomon S. 2014. The coordination role in research education: Emerging understandings and dilemmas for leadership. Journal of Higher Education Policy and Management, 36(4):440-454.

Bourdieu P. 1987. What makes a social class? On the theoretical and practical existence of groups. Berkeley Journal of Sociology, 32:1-17.

Brew A. 2015. The paradoxical university and the public good. In: O Filippakou \& G Williams (eds). Higher education as a public good. Critical perspectives on theory, policy and practice. New York: Peter Lang. 97-112. 


\section{POSTGRADUATE SUPERVISION • FUTURE FOCI FOR THE KNOWLEDGE SOCIETY}

Croussard B. 2013. Conceptualising doctoral researcher training through Bernstein's theoretical frameworks. International Journal for Researcher Development, 4(2):72-85.

Danby S \& Lee A 2012 Framing doctoral pedagogy as design and action. In A Lee \& S Danby (eds). Reshaping doctoral education: International approaches and pedagogies. Abington: Routledge.

Golde CM \& Walker GE. (eds). 2006. Envisioning the future of doctoral education. San Francisco, CA: Jossey Bass.

LERU (League of European Research Universities). 2010. Doctoral degrees beyond 2010: Training talented researchers for society. Leuven: LERU.

Mc Alpine L, Amundsen C \& Turner G. 2013. Constructing post-PhD careers: Negotiating opportunities and personal goals. International Journal for Researcher Development, $4(1): 39-54$.

Mc Alpine L \& Norton J. 2006. Reframing our approach to doctoral programs: An integrative framework for action and research. Higher Education Research and Development, 25(1):317.

Nerad M \& Evans B. (eds). 2014. Globalisation and its impacts on the quality of PhD education: Forces and forms in doctoral education worldwide. Rotterdam: Sense.

Scott P. 2015. Higher education, the public good and public interest. In: $O$ Filippakou \& $G$ Williams (eds). Higher education as a public good. Critical perspectives on theory, policy and practice. New York: Peter Lang. 41-58.

Singh M. 2015. Institutionalising the public good: Conceptual and regulatory challenges. In: O Filippakou \& G Williams (eds). Higher education as a public good. Critical perspectives on theory, policy and practice. New York: Peter Lang. 59-74.

Taylor SE. 2012. Changes in doctoral education: Implications for supervisors in developing early career researchers. International Journal for Researcher Development, 3(2):1 18-138.

Tight M. 2003. Researching higher education. Berkshire: Society for Research into Higher Education \& Open University Press.

UNESCO. 2005. Towards knowledge societies. UNESCO World Report. Paris: UNESCO Publishing.

Välimaa J \& Hoffman D. 2008. Knowledge society discourse and higher education. Higher Education, 56:265-285. 